\title{
Vínculos com a Carreira e Produção Acadêmica: Comparando Docentes de IES Públicas e Privadas
}

Links between Career and Academic Performance: Comparing Teachers at Private and Public Higher Education Establishments in Brazil permitido citar parte de artigos sem autorização prévia, desde que seja identificada a fonte. 


\title{
RESUMO
}

A pesquisa sobre o vínculo do profissional com a sua carreira envolve dois construtos - o de comprometimento e o de entrincheiramento, cujas influências no desempenho ainda estão por ser mais bem compreendidas. Este trabalho teve o objetivo de analisar a influência destes dois vínculos com a carreira na produção acadêmica do docente inseridos nos contextos público e privado do ensino superior brasileiro. A pesquisa, de natureza extensiva e corte transversal, envolveu a aplicação de um questionário, mediante a internet, a uma amostra de 635 docentes de diferentes regiões do país. Utilizaram-se as escalas de Carson e Bedeian (1994) e Carson, Carson e Bedeian (1995), validadas para o contexto brasileiro, para avaliar comprometimento e entrincheiramento na carreira. A avaliação da produção acadêmica do docente envolveu a sua produção bibliográfica registrada no Currículo Lattes, como utilizado por Oliveira (1998). Os dados foram submetidos a análises descritivas, fatoriais e modelagens de equações estruturais. O modelo com melhor ajuste revela que quanto mais o docente investe tempo e dinheiro em sua carreira, maior é a sua produção acadêmica. Foram encontradas, também, diferenças nas influências dos dois vínculos com a carreira na produção acadêmica entre IES públicas e privadas.

Palavras-chave: entrincheiramento na carreira; comprometimento com a carreira; produção acadêmica; docente do ensino superior.

\begin{abstract}
Research into the relationship between work and career involves two constructs - commitment and entrenchment, whose influence on performance have yet to be fully understood. The main goal of this study is to analyze the influences of the dimensions of links with the academic career of teaching in the contexts of public and private higher education in Brazil. This research is extensive in nature and cross-sectional. For data collection, a questionnaire which had previously been validated for the Brazilian context was applied containing a set of scales to measure career commitment and entrenchment. The links with the careers were measured by the scales proposed and validated by Carson and Bedeian (1994) and Carson, Carson and Bedeian (1995), while the performance of teachers includes points taken from their Curriculum Vitae of the Lattes Database, in accordance with the practice used by Oliveira (1998). We surveyed 635 teachers, whose data were submitted to descriptive analysis, factor analysis and structural equation modeling. The best fit model reveals that the more time and money teachers invest in their careers, the greater their academic performance will be. We also found differences in the influences of the two links to career in academic performance between private and public higher education establishments.
\end{abstract}

Key words: career entrenchment; career commitment; links with career; performance; higher education teaching staff. 


\section{INTRODUÇÃO}

Os vínculos com a carreira têm-se tornado, crescentemente, relevantes, em face das mudanças do mundo do trabalho, como estas: reestruturação organizacional, aumento da percepção do trabalhador a respeito da insegurança do trabalho e o crescimento da força de trabalho. Nesse contexto, autores como Blau (2003) e Cohen (2003) apontam que o foco primordial do comprometimento do trabalhador pode estar mudando da organização para a carreira.

Nas pesquisas atuais sobre a relação do trabalhador com a sua carreira, destacam-se, além do comprometimento, o entrincheiramento. Trata-se de dois construtos voltados para a explicação da persistência do trabalhador em um curso de ação que delimita a sua ocupação e os investimentos que faz, de forma a construir uma trajetória exitosa, tanto no plano pessoal quanto nos resultados que gera para a sociedade.

Dentre estes vínculos com a carreira, a vertente mais antiga de pesquisa que utiliza o conceito de comprometimento na carreira enfatiza a importância deste vínculo por ser preditor de quanto o trabalhador investe no seu crescimento profissional, qual o seu desempenho extra para manter-se atualizado na profissão e responder às expectativas sociais que cercam o seu exercício profissional, segundo Bastos (1997).

Por outro lado, mais recentemente, surge o conceito de entrincheiramento, para abarcar uma postura estática e defensiva adotada pelo trabalhador, em face das incertezas e inseguranças que marcam as transições no mundo do trabalho e que termina constituindo-se obstáculo para investimento em nova carreira. O entrincheiramento pode, então, ser entendido como uma resposta à realidade contemporânea do mundo do trabalho, segundo Baiocchi e Magalhães (2004). O entrincheiramento consiste na persistência na mesma linha de ação profissional por falta de opções de carreira, pela sensação de perda dos investimentos já realizados, ou pela percepção de uma consequência emocional muito alta em caso de mudança de carreira. Em síntese, estes dois vínculos se reportam a atitudes em face das carreiras que têm o potencial de gerar comportamentos muito distintos, com impactos pessoais, organizacionais e sociais expressivos.

Na origem desta pesquisa está a pretensão de preencher algumas lacunas de estudos sobre vínculos com a carreira, mencionadas por autores nacionais e internacionais. Scheible, Bastos e Rodrigues (2007) ressaltam a necessidade de mais pesquisas nacionais acerca do comprometimento com a carreira e do entrincheiramento na carreira. Lee, Carswell e Allen (2000) sugerem o estudo da relação dos construtos comprometimento com a carreira e desempenho, tema ainda pouco explorado. Carson, Carson, Phillips e Roe (1996) assinalam a necessidade de pesquisas que possam contribuir para um maior entendimento de entrincheiramento na carreira, como também verificar a sua relação com o desempenho. Blau (2001), por sua vez, indica que se faz necessária a realização de estudo que abarque o comprometimento com a carreira e o entrincheiramento na carreira, assim como a necessidade de investigar os consequentes destes dois vínculos com a carreira. Sabendo-se que as motivações para tornar-se e permanecer entrincheirado podem ser significativas e efetivas para muitos sujeitos, cabe examinar, adicionalmente, as implicações práticas destes vínculos com a carreira, tanto para os trabalhadores quanto para as organizações, segundo Carson et al. (1996).

A escolha de estudar o docente se justifica, porque no Brasil, esta categoria apresenta peculiaridades complexas. O docente do ensino superior trabalha em diferentes tipos de instituições, desenvolve nelas atividades que se qualificam de diferentes formas, enfrenta tensões das mais variadas, seja com os pares dela ou de diferentes áreas; é um profissional não apenas e necessariamente da instituição do ensino superior [IES] e mostra diferentes relações com o conhecimento, seja para produzi-lo seja para disseminá-lo. Caracteriza-se pela diversidade, pela pluralidade de opções, caminhos, alternativas, interesses e tensões.

O docente apresenta relevância estratégica nas IES, uma vez que é peça-chave nestas instituições, especificamente quanto à sua atuação na educação e na pesquisa. Essa categoria tem vivenciado um 
crescimento vertiginoso nos últimos anos pela expansão do ensino superior no Brasil, que é um dos países com uma das maiores redes de educação superior em termos mundiais: a maior da América do Sul e a sétima no mundo, enquanto os Estados Unidos são a vigésima (Anteprojeto de lei da educação superior, 2005). Este crescimento da educação no segmento privado trouxe novas relações e condições de trabalho para o docente do ensino superior e estas relações de trabalho, embutidas neste novo cenário, desafiam a investigação dos seus possíveis impactos nos vínculos com a carreira e no desempenho do docente.

Nesse cenário, surge um tema de pesquisa relevante. Trata-se do desempenho do trabalhador e vínculos com a carreira. Dentro desse tema, um problema de pesquisa se apresenta: Como os vínculos com a carreira impactam a produção acadêmica dos docentes do ensino superior? Mais precisamente, objetiva-se com este trabalho analisar as dimensões dos vínculos com a carreira entrincheiramento e comprometimento - que explicam a produção acadêmica do docente do ensino superior, comparando o contexto público e privado do ensino superior brasileiro.

Para tanto, após esta introdução, este artigo faz uma apresentação geral da literatura sobre os vínculos com a carreira: comprometimento e entrincheiramento. Em seguida, descreve as decisões metodológicas envolvidas na construção da pesquisa empírica. A próxima parte apresenta e discute os resultados obtidos, relatando o material coletado entre docentes do ensino superior de todo o Brasil, de IES públicas e privadas, o que é base para as conclusões finais do trabalho.

\section{Um OlHar nos Vínculos com a Carreira}

No cenário socioeconômico contemporâneo, as estruturas organizacionais e as expectativas do trabalho não apenas estão requerendo um trabalhador mais flexível e inteligente, mas também estão forçando o trabalhador a ter o máximo de controle sobre sua vida no trabalho e sobre a sua carreira. A lealdade à organização tornou-se um valor não usual, remanescente de um tempo mais tranquilo e amistoso; e a noção de comprometimento do trabalhador passou a requerer dedicação individual ao treinamento contínuo, atualização e troca de habilidades e perícias individuais (Gottlieb \& Conkling, 1995).

O conjunto de transformações pelas quais vem passando o mundo do trabalho afeta tanto organizações quanto trabalhadores, resultando em impactos nos relacionamentos destes atores, até mesmo no aspecto construção de carreiras. Desta forma, os trabalhadores dificilmente conseguem sustentação para o desenvolvimento de suas carreiras em uma única organização (Nussbaum, 1991 como citado em Carson \& Bedeian, 1994). Em face desta realidade, o compromisso com a carreira pode fornecer significado e continuidade no trabalho aos trabalhadores, nestes tempos em que as organizações se tornaram fluídas e incapacitadas a prover estabilidade no emprego (Colarelli \& Bishop, 1990 como citado em Carson \& Bedeian, 1994), contribuindo para o fato de que a carreira representa o principal foco na vida de muitas pessoas (Cohen, 2003; Lee et al., 2000).

A presente seção apresenta uma revisão da literatura acerca de comprometimento com a carreira e entrincheiramento na carreira, que são os vínculos com a carreira integrantes do objeto de estudo desta pesquisa.

\section{Comprometimento com a Carreira}

O comprometimento com a carreira é, dentre os focos de comprometimento - organização, valores, carreira, trabalho e sindicato, como indicados por Morrow (1983) - aquele menos desenvolvido (Aryee \& Tan, 1992; Bastos, 1994; Carson \& Carson, 1997). Carson e Carson (1997) apontam que esta lacuna é particularmente problemática em face da evidência de que a estabilidade na carreira é motivada mais por vínculos de ordem econômica do que por vínculos ligados a emoções. 
Cooper-Hakim e Viswesvaran (2005) definem o comprometimento com a carreira como dedicação ou compromisso de uma pessoa com sua profissão, ocupação ou carreira. Assim, uma pessoa com alto comprometimento ocupacional se identifica fortemente e tem sentimentos positivos em relação a sua ocupação. Nesse sentido, Bastos (1994) complementa que o comprometimento está ligado à consistência de linha de ação e rejeição de alternativas possíveis.

Estudos internacionais identificaram associações entre o comprometimento com a carreira e variáveis importantes para o comportamento organizacional. Na sequência, discorre-se sobre os achados mais relevantes destas relações.

Wallace (1993) e Carson e Bedeian (1994) verificaram que o comprometimento com a carreira possui correlação positiva com o desempenho, com o comprometimento organizacional e com a busca de desenvolvimento de habilidades, e correlação negativa com rotatividade e intenções de abandonar a carreira, não sendo considerado preditor da qualidade de trabalho, conforme se encontra sumariado na Tabela 1.

Lee et al. (2000) verificaram que o comprometimento com a carreira foi moderadamente e positivamente correlacionado com avaliação de desempenho pelo supervisor $(\mathrm{r}=.219)$. E apontam que esta correlação é mais forte do que a correlação entre desempenho e comprometimento organizacional ( $\mathrm{r}=.135$ de Mathieu \& Zajac, 1990). Entretanto alertam que este resultado deve ser interpretado com cautela, devido ao pequeno número de estudos desta relação, cinco, e pelo tamanho desta amostra $(\mathrm{N}=$ 746).

Tabela 1

\section{Variáveis e suas Relações com o Comprometimento com a Carreira}

\begin{tabular}{ll}
\hline Variáveis & Referências \\
\hline Correlação positiva & Wallace (1993); Carson e Bedeian (1994). \\
$\begin{array}{l}\text { Desempenho } \\
\text { Avaliação de desempenho pelo supervisor }\end{array}$ & Lee et al. (2000). \\
Comprometimento organizacional & Wallace (1993); Carson e Bedeian (1994). \\
$\begin{array}{l}\text { Comprometimento organizacional afetivo } \\
\text { Comprometimento organizacional normativo }\end{array}$ & Mathieu e Zajac (1990); Lee et al. (2000). \\
Busca de desenvolvimento de habilidades. & Wallace (1993); Carson e Bedeian (1994). \\
$\begin{array}{l}\text { Correlação negativa } \\
\text { Comprometimento organizacional instrumental } \\
\text { Rotatividade }\end{array}$ & Lee et al. (2000). \\
Intenção de abandonar a carreira & Wallace (1993); Carson e Bedeian (1994). \\
& Wallace (1993); Carson e Bedeian (1994); \\
\hline
\end{tabular}

Nota. Fonte: elaborado pelos autores.

A pesquisa sobre comprometimento com a carreira obteve um modelo multidimensional proposto por Carson e Bedeian (1994). Neste modelo, a mensuração do construto comprometimento com a carreira utiliza uma escala com três dimensões e quatro itens cada uma, que mensuram dimensões de identidade, resiliência e planejamento de carreira. Identidade é o apego emocional à própria carreira. Planejamento de carreira consiste na determinação de necessidades de desenvolvimento e estabelecimento de metas de carreira. Resiliência consiste no componente de persistência do comprometimento perante a adversidade, é a resistência à ruptura da carreira em face de adversidades. 
Segundo Somech e Bogler (2002), o comprometimento com a carreira é necessário em parte porque profissionais de áreas tão diversas, como medicina, militar e educação, têm de tomar decisões rapidamente, que não podem ser supervisionadas facilmente por terceiros e seus clientes não têm conhecimento suficiente para avaliar o serviço recebido. Especificamente quanto à docência, as escolas têm dificuldades em observar docentes, avaliar seu desempenho e suas práticas específicas obrigatórias; portanto, docente comprometido com sua carreira é crucial para se obter um ensino de qualidade.

\section{Entrincheiramento na Carreira}

O entrincheiramento na carreira consiste numa imobilidade resultante de substancial investimento econômico e psicológico em uma carreira, o que torna difícil uma mudança de carreira (Carson et al., 1996). O entrincheiramento na carreira é conceitualizado por Carson, Carson e Bedeian. (1995) como construto multidimensional, com três componentes, discutidos a seguir. (a) Investimentos na carreira, que seriam perdidos ou menos aproveitados com uma mudança na carreira (Meyer \& Allen, 1984). Refere-se a tempo investido, dinheiro e/ou esforço relativo à capacitação profissional, cargo e salário. (b) Custos emocionais antecipados com uma mudança de carreira (Hirsch, 1987), que envolvem questões sociais e psicológicas associadas à ruptura de relações interpessoais que uma mudança de carreira traria, como quebra de vínculos profissionais. (c) Falta de alternativas de carreira, que consiste na percepção de perda de opções disponíveis com uma mudança de carreira ou opção em uma nova carreira.

O entrincheiramento apresenta sintomas que podem incluir: desejo de evitar estigma social, medo de que a idade e habilidades específicas limitem uma boa recolocação, falta de desejo de deixar privilégios já adquiridos, medo de perder com a troca, ou seja, o ceticismo sobre o potencial de ganhos financeiros fora da posição atual também pode ser considerado sintomático do entrincheiramento. Nesse sentido, há indicação empírica de que pessoas que seguem carreiras tradicionais ganham mais ao longo da vida do que pessoas que trocam de carreira (Carson et al., 1995).

Trabalhadores que mudam de carreira perdem não somente investimentos financeiros, mas também esforços associados à obtenção de titulação acadêmica e de habilidades específicas à carreira. A mudança de carreira também envolve rompimentos difíceis na identidade própria, no status social e em relacionamentos interpessoais. Estes side-bets econômico e psicológico podem ser interpretados como custos irrecuperáveis, ao contemplar decisões sobre mudança de carreira. O processo de investir e de manter a estabilidade sociopsicológica desvia energia individual de fazer uma busca no ambiente de alternativas viáveis de carreira. Como os estímulos externos são ignorados, trabalhadores experimentam uma constrição em sua percepção de opções de carreira; com o passar do tempo, estas alternativas diminuem (Carson \& Carson, 1997).

Trabalhadores que investiram significativamente em: (a) educação/treinamento; (b) despenderam esforços e tempo; e (c) o relacionamento interpessoal, relacionado a sua carreira, implica, provavelmente, que a pessoa está mais entrincheirada na carreira do que aquela que não fez investimentos significantes, segundo Carson e Carson (1997).

Na seleção de carreira o trabalhador inicia o processo de investimento. Posteriormente, quantidade crescente de tempo, dinheiro e esforços vão sendo dedicados para treinamento e preparação da demanda da carreira (Osherson, 1980 como citado em Carson et al., 1996). Ressalta-se que os investimentos não param com educação. Após a capacitação inicial, trabalhadores motivados com a carreira continuam dispensando muita energia em sua vocação. Este esforço frequentemente resulta em oportunidades de trabalho enriquecidas, compensação mais alta e aumento da autoridade, que são fatores relacionados ao cumprimento da função e satisfação (Aryee, Chay, \& Mastigue, 1994; Zeitz, 1990 como citado em Carson et al., 1996).

A propensão ao risco também pode influenciar a habilidade do trabalhador em identificar alternativas de carreira, de acordo com Carson e Carson (1997). Aqueles que toleram riscos provavelmente evitam mais o entrincheiramento na carreira do que aqueles que têm aversão ao risco. Mudança de carreira é 
para trabalhador arrojado, pois uma nova carreira pode demandar sacrifícios profundos e também pode envolver aprendizagem e novas habilidades. Como fracasso pessoal é uma possibilidade, mudança de carreira abarca risco e alto amor próprio para tolerar potenciais retrocessos. Nesse sentido, oportunidades de carreira também podem ser limitadas por: (a) energia focada na justificação, em detrimento de focar na procura de uma carreira alternativa; (b) baixa motivação pessoal ou habilidade; e (c) discriminação de idade. Além disso, fatores pessoais (como mudança no status da família) e econômicos (como taxa de desemprego) também são relacionados à percepção de alternativas de carreira.

Carson e Carson (1997) debatem o seguinte: extremos de entrincheiramento, ou seja, taxa de mobilidade muito baixa ou, no inverso, excessiva mobilidade de carreira, não é bom. A alta mobilidade de carreira afeta a aprendizagem organizacional; como consequência, resulta a competitividade da organização, a perda da memória da organização, custos excessivos para gerenciar as pessoas (como recrutamento, seleção e treinamento) e burnout do trabalhador. Por outro lado, o excessivo entrincheiramento é causado por baixo nível de motivação e habilidades obsoletas, o que também não é bom nem para a organização nem para o trabalhador.

O objetivo de estudar a relação entre vínculos com a carreira e desempenho entre docentes, coloca o desafio de escolher que dimensões do desempenho docente poderiam ser tomadas como objeto da pesquisa. A complexidade do desempenho docente e a multiplicidade de produtos que gera colocam várias alternativas ao pesquisador; optou-se, neste trabalho, pela produção acadêmica, por várias razões. A primeira, a própria relevância da produção acadêmica, destacada pela LDB, quando afirma que a educação superior tem por finalidade, além daquela de formar profissionais nas diferentes áreas do conhecimento, incentivar o trabalho de pesquisa e promover a divulgação deste conhecimento acadêmico, que constitui patrimônio da humanidade, e comunicar o saber por meio do ensino, de publicações ou de outras formas de comunicação (Lei n. 9.394, 1996). O papel da academia é criar e disseminar conhecimento na sociedade, sendo que a produção do conhecimento é a origem do ensino e da extensão.

Segundo Moita (2002), a produtividade de docentes/pesquisadores e seu impacto na sociedade vêm ganhando crescente importância, não só no âmbito das agências de fomento e das universidades, que necessitam quantificar os efeitos de sua atuação no sistema nacional de ciência e tecnologia, como também entre o público e a mídia, que almejam conhecerem quão bem aplicados têm sido os recursos públicos.

A produção científica brasileira tem dado claras demonstrações de crescimento, tanto em número quanto em qualidade. O Brasil apresenta índices de crescimento na produção científica superiores à média americana e da comunidade européia e este potencial de crescimento científico do Brasil está ancorado na excelente e bem distribuída pós-graduação do país (Anteprojeto de lei da educação superior, 2005). Justifica-se assim, a importância de se estudar as influências dos vínculos com a carreira na produção científica.

Além das considerações anteriores que apontam a centralidade da produção acadêmica como resultado esperado do desempenho do professor de ensino superior, há que destacar o fato de a produção acadêmica poder ser avaliada de forma independente da informação do docente. $\mathrm{O}$ trabalho estaria, então, contribuindo para estabelecer relações possíveis entre fenômenos que são mensurados independentemente, diferenciando-se da maior parte das pesquisas sobre consequentes do comprometimento, que toma como consequentes intenções e/ou atitudes informadas pelos próprios participantes.

\section{MÉTODO}

Para este estudo, optou-se por aplicar survey por e-mail, porque docente de ensino superior é uma categoria ocupacional que, além do alto nível de escolaridade, geralmente tem acesso e utiliza e-mail, tanto 
no lar quanto nas IES, o que justifica a sua adoção, além de ser o melhor método de survey para atingir docentes de ensino superior em todo o Brasil, de uma forma rápida e com baixo custo operacional.

Para o alcance dos objetivos delineou-se um estudo transversal, quantitativo, descritivo e explicativo, de forma a proporcionar a análise da natureza e da dinâmica dos vínculos com a carreira e seu impacto no desempenho acadêmico. Descritiva, porque busca explicitar as características de determinada população ou de determinado fenômeno, podendo também estabelecer correlações entre variáveis e definir sua natureza. Explicativa, porque procura tornar o fenômeno sob investigação, inteligível, justificando os motivos e os fatores que contribuem para a sua ocorrência, segundo Vergara (2007). Este estudo toma como unidade de análise o trabalhador, que envolve o docente de ensino superior.

\section{Instrumento de Coleta de Dados}

Os itens para levantamento dos dados demográficos e ocupacionais foram elaborados para esta pesquisa, que são: idade, gênero, estado civil, última titulação, área de atuação, tempo de serviço, Estado, natureza da IES (pública ou privada), regime de trabalho (DE, tempo parcial, horista), e se ocupa cargo de chefia.

O presente estudo utilizou os instrumentos propostos por Carson e Bedeian (1994) e Carson et al. (1995) para mensurar comprometimento e entrincheiramento na carreira. Ambas as escalas, em formato Likert, possuem 12 itens que cobrem as três dimensões que integram cada um dos construtos. Por se tratar de estudo de segmento ocupacional específico e distinto daqueles em que foram validadas as escalas utilizadas, uma primeira análise envolveu o teste da estrutura fatorial destas escalas, assim como os indicadores de fidedignidade das medidas.

Os resultados da análise fatorial dos 12 indicadores da escala de entrincheiramento na carreira, utilizando-se para a extração dos fatores o método dos componentes principais com eigenvalue maior que um e a rotação varimax, revela a mesma estrutura original com três dimensões, cada uma com quatro itens. A matriz de correlação entre os itens apresenta determinante de 0,003, KMO de 0,84 e teste de esfericidade de Bartlett com significância de 0,000. Os três fatores da escala explicam 69,68\% da variância total. Quanto à confiabilidade da medida, obteve-se um alpha de Cronbach de 0,84, considerado por Hair, Anderson, Tatham e Black (2005) como um índice elevado e satisfatório. Os alphas de Cronbach por fator se situam acima de 0,82. A Tabela 2 apresenta os alphas de Cronbach da escala de entrincheiramento na carreira obtidos nesta pesquisa, comparando-os com a pesquisa original e outros estudos realizados no Brasil.

Tabela 2

\section{Confiabilidade da Escala de Entrincheiramento na Carreira}

\begin{tabular}{lccccc} 
& \multicolumn{5}{c}{ Alpha de Cronbach } \\
\cline { 2 - 6 } $\begin{array}{l}\text { Escala de entrincheiramento na } \\
\text { carreira de Carson et al. (1995) e suas } \\
\text { dimensões }\end{array}$ & $\begin{array}{c}\text { ESTA } \\
\text { PESQUISA }\end{array}$ & $\begin{array}{l}\text { Original: } \\
\text { Carson et } \\
\text { al. (1995) }\end{array}$ & $\begin{array}{l}\text { Jardim } \\
\text { (2002) }\end{array}$ & $\begin{array}{l}\text { Magalhães } \\
\text { (2005) }\end{array}$ & $\begin{array}{l}\text { Scheible e } \\
\text { Bastos } \\
\text { (2006) }\end{array}$ \\
$\begin{array}{l}\text { Escala de entrincheiramento na carreira } \\
\text { Suas três dimensões }\end{array}$ & 0,84 & 0,88 & 0,85 & 0,84 & 0,84 \\
Custos emocionais & 0,82 & 0,88 & Não & 0,73 & 0,82 \\
$\begin{array}{l}\text { Falta de alternativas de carreira } \\
\text { Investimentos na carreira }\end{array}$ & 0,88 & 0,85 & apresenta & 0,72 & 0,86 \\
\hline
\end{tabular}

Nota. Fonte: elaborado pelos autores. 
Para a análise fatorial dos 12 indicadores da escala de comprometimento com a carreira de Carson e Bedeian (1994), adotou-se para a extração dos fatores o método dos componentes principais com eigenvalue maior que um e a rotação varimax, revelando a mesma estrutura original com três dimensões, tendo-se perdido apenas um item. A matriz de correlação entre os itens apresenta determinante de 0,009, KMO de 0,78 e teste de esfericidade de Bartlett com significância de 0,000. Os três fatores da escala explicam 67,36\% da variância total. Quanto à confiabilidade geral da medida, os resultados podem ser vistos na Tabela 3 que discrimina os alphas da escala de comprometimento com a carreira de Carson e Bedeian (1994), também os comparando com os alphas encontrados nesta pesquisa e nos outros três estudos que foram realizados no contexto nacional. Tais alphas, embora ligeiramente mais baixos do que os da escala de entrincheiramento, revelam-se bastante aceitáveis e promissores, pois segundo Hair et al. (2005), o limite inferior para o alpha de cronbach geralmente aceito é de até 0,70 , apesar de poder diminuir para 0,60 em pesquisa exploratória.

Tabela 3

Confiabilidade da Escala de Comprometimento com a Carreira de Carson e Bedeian (1994)

\begin{tabular}{|c|c|c|c|c|c|}
\hline \multirow[b]{2}{*}{$\begin{array}{l}\text { Escala de comprometimento com a } \\
\text { carreira de Carson e Bedeian (1994) } \\
\text { e suas dimensões }\end{array}$} & \multicolumn{5}{|c|}{ Alpha de Cronbach } \\
\hline & $\begin{array}{l}\text { ESTA } \\
\text { PESQUISA }\end{array}$ & $\begin{array}{l}\text { Original: } \\
\text { Carson e } \\
\text { Bedeian } \\
(1994)\end{array}$ & $\begin{array}{l}\text { Jardim } \\
(2002)\end{array}$ & $\begin{array}{l}\text { Magalhães } \\
\text { (2005) }\end{array}$ & $\begin{array}{l}\text { Scheible et } \\
\text { al. (2007) }\end{array}$ \\
\hline $\begin{array}{l}\text { Escala de comprometimento com a } \\
\text { carreira }\end{array}$ & 0,79 & 0,81 & 0,84 & 0,82 & 0,82 \\
\hline \multicolumn{6}{|l|}{ Suas três dimensões } \\
\hline Identidade & 0,78 & 0,79 & \multirow{3}{*}{$\begin{array}{l}\text { Não } \\
\text { apresenta }\end{array}$} & 0,75 & 0,76 \\
\hline Resiliência & 0,86 & 0,79 & & 0,72 & 0,82 \\
\hline Planejamento de carreira & 0,75 & 0,85 & & 0,76 & 0,80 \\
\hline
\end{tabular}

Fonte: elaborado pelos autores.

Para o presente estudo optou-se por utilizar como indicador do desempenho docente a sua produção acadêmica, por ser um indicador objetivo do desempenho, independe de informações fornecidas pelo próprio respondente, algo pouco costumeiro nesse campo de pesquisa. Nesse sentido, faz-se necessário destacar que nem toda atividade do docente resulta diretamente em produção acadêmica, como, por exemplo: preparação das disciplinas (antigas e novas); as aulas propriamente ditas; atendimento ao aluno; participação em bancas examinadoras de estágio supervisionado, iniciação científica, defesas de mestrado e defesas de doutorado. As orientações de estágio supervisionado e de monografias, por sua vez, nem sempre resultam em produção acadêmica.

A escala de produção acadêmica utilizada nesta pesquisa foi adaptada de Oliveira (1998) e consiste na quantidade de produção acadêmica num intervalo de seis anos, coletados no currículo Lattes de cada docente participante desta pesquisa. Esta escala é formada pelos seguintes quantitativos: artigos publicados em periódicos (nacionais e internacionais); artigos completos em anais de congressos (nacionais e internacionais); teses, dissertações e monografias de especialização orientadas e concluídas; livros publicados; coordenação de projetos de pesquisa e bolsa de produtividade científica.

Este indicador objetivo foi adotado, porque a educação superior tem por finalidade, além daquela de formar profissionais nas diferentes áreas do conhecimento, incentivar o trabalho de pesquisa e promover a divulgação deste conhecimento acadêmico, comunicando o saber por meio do ensino, de publicações ou de outras formas de comunicação. O papel da academia é criar e disseminar o conhecimento na sociedade, sendo que a produção do conhecimento é a origem do ensino e da extensão. Em suma, a função da academia não é somente ensinar, e a pesquisa também é tão importante quanto o ensino. 
Assim como nas escalas de comprometimento e entrincheiramento na carreira, na escala de produção acadêmica foi realizada análise fatorial, que resultou em quatro fatores. $\mathrm{O}$ primeiro fator, orientação, formado pelas variáveis orientação de mestrado e orientação de doutorado. O segundo fator, bolsa, composto das variáveis coordenação de projetos de pesquisa e bolsa de produtividade acadêmica. O terceiro fator, denominado publicação, consiste nas publicações em periódicos nacionais e internacionais; o último fator, que foi nomeado de anais, representa as publicações em congressos científicos nacionais e internacionais. As outras duas variáveis, livros e orientações de monografias de especialização foram eliminadas por apresentarem baixa carga fatorial.

\section{Procedimentos para Coleta, Tratamento e Análise dos Dados}

Para viabilizar a coleta de dados em todo o território nacional, como também para facilitar o acesso aos docentes de todos os tipos de IES, esta pesquisa utilizou a coleta on-line. A sua aplicação via Internet poderia ter dois caminhos: o envio do questionário por e-mail, ou hospedar o questionário em uma página na Internet e enviar um e-mail com o link do questionário, sendo este o procedimento utilizado para esta pesquisa.

Após o término da elaboração e da formatação do instrumento de coleta de dados, ele foi hospedado em uma página da Internet, que envolveu vários testes e ajustes da página e do banco de dados. Após sanar todas as inconsistências, houve a divulgação do endereço eletrônico desta página para o préteste, que foi realizado com 15 docentes de IES públicas e 15 docentes de IES privadas. A escolha dos participantes do pré-teste ocorreu entre docentes conhecidos de diversas IES e de diversas áreas, dando-se ênfase aos docentes com mais experiência em pesquisa acadêmica, para se obter o melhor feedback possível. Após a análise do resultado deste pré-teste, referente tanto ao instrumento quanto à página da Internet, foram realizados alguns poucos ajustes necessários, iniciando-se em seguida a coleta de dados.

A solicitação para o docente participar desta pesquisa foi realizada por e-mail explicativo dos seus fins acadêmicos, contendo o link do endereço da página da Internet hospedeira do questionário. Esta pesquisa foi divulgada em diversas comunidades de docentes de IES de todo o Brasil. Do mesmo modo, ainda no ambiente acadêmico, foi encaminhada para sindicatos, reitorias, departamentos, coordenações e secretarias, solicitando sua divulgação, de forma a repassar para os e-mails dos docentes. Assim como foram rastreadas listas de e-mails de docentes no site de busca Google, como também foram realizadas buscas de e-mails na página da Capes. Os e-mails foram enviados individualmente, para que não fossem direcionados para o spam e, consequentemente, poderia ser perdida a possibilidade de ser lido pelo docente. A coleta de dados priorizou um equilíbrio entre respondentes de IES públicas e privadas e a participação de docentes de todos os Estados brasileiros e do Distrito Federal. O referido convite para participar da pesquisa ainda solicitava que o próprio docente o encaminhasse para sua lista de docentes do ensino superior. Muitos docentes fizeram a divulgação da pesquisa entre seus contatos, com cópia para os pesquisadores. Dessa forma, obteve-se a participação de 635 docentes de todas as áreas do conhecimento e de toda a extensão do Território Nacional.

Salienta-se que os dados da produção acadêmica dos docentes que responderam o questionário foram coletados somente por um pesquisador na plataforma do currículo Lattes do CNPq. Esta centralização ocorreu com o intuito de se evitar viés.

Na etapa de análise, primeiramente os dados coletados foram transportados para o Statistical Package for Social Sciences [SPSS] versão 15.0 e em seguida foram tratados, conforme princípios definidos por Hair et al. (2005) e Malhotra (2006). Foi realizada a análise exploratória dos dados, a avaliação da normalidade, outliers, análise de linearidade e análise de multicolinearidade. Em seguida, foi realizada a análise da qualidade da mensuração das escalas, cumprindo-se as etapas de análise de dimensionalidade, confiabilidade e validade das medidas (convergente e discriminante). Com a confirmação da consistência dos dados com todos estes testes, partiu-se para realizar a modelagem de equações estruturais, com o método de máxima verossimilhança. 


\section{RESULTADOS E DISCUSSÃo}

Participaram desta pesquisa 635 docentes de todas as regiões do Brasil e de todas as áreas do conhecimento, de 201 diferentes IES, das quais 65 são públicas e 136 são IES privadas. Entre os docentes participantes desta pesquisa, 55,1\% têm vínculo empregatício com IES pública e 44,9\% com IES privada. Quanto ao gênero, há um equilíbrio entre professores $(49,6 \%)$ e professoras $(50,4 \%)$ participantes desta pesquisa; 60\% dos docentes são casados; a idade média é de 43 anos e 50,7\% são doutores.

Após esta breve caracterização da amostra participante da pesquisa, esta seção apresenta os dados descritivos da produção acadêmica e dos vínculos com a carreira. Em seguida, apresenta-se o modelo de equações estruturais que mostra a influência das dimensões dos vínculos com a carreira no desempenho acadêmico do docente, oferecendo e discutindo respostas à questão central deste trabalho.

\section{Dados Descritivos das Variáveis da Pesquisa: Produção Acadêmica, Comprometimento e Entrincheiramento na Carreira}

A Tabela 4 apresenta a média e o desvio padrão da produção acadêmica dos docentes participantes desta pesquisa, num intervalo de seis anos. Observa-se que a média da produção acadêmica se revela baixa, destacando-se a maior produção em periódicos e congressos nacionais do que nos internacionais.

Tabela 4

\section{Produção Acadêmica}

\begin{tabular}{lccc}
\hline Produção acadêmica & Média & Desvio padrão & Quantitativo \\
\hline Periódico nacional & 3,14 & 4,560 & 635 \\
Periódico internacional &, 65 & 1,412 & 635 \\
Anais nacionais & 3,59 & 5,447 & 635 \\
Anais internacionais & 1,55 & 2,901 & 635 \\
Livros &, 75 & 1,403 & 635 \\
Coordenação de projeto de pesquisa &, 60 & 1,063 & 635 \\
\hline
\end{tabular}

Nota. Fonte: dados da pesquisa.

A Tabela 5 apresenta as médias dos vínculos com a carreira, diferenciando os dois contextos, público e privado, e apresenta o nível de significância das diferenças observadas. A expectativa é que os contextos público e privado diferem fortemente no tocante às condições oferecidas ao docente de ensino superior no tocante à sua carreira. Enquanto as instituições públicas fornecem estabilidade e oportunidades de qualificação continuada, no setor privado não há estabilidade para o trabalho dos seus docentes. Os dados desta análise, constantes na Tabela 5, revelam que a natureza da instituição não influencia o vínculo do docente com a sua carreira, seja na análise por fatores seja na escala total, tanto no comprometimento com a carreira quanto no entrincheiramento na carreira. 
Tabela 5

Comprometimento e Entrincheiramento entre Docentes das IES Públicas e Privadas

\begin{tabular}{llllll}
\hline Dimensões & Média & & & & Sig. \\
& Pública & Privada & Total & & \\
Comprometimento com a carreira & $\mathbf{5 , 6 1}$ & $\mathbf{5 , 5 8}$ & $\mathbf{5 , 6 0}$ & 0,246 & 0,620 \\
Resiliência & 4,33 & 4,26 & 4,30 & 0,315 & 0,575 \\
Planejamento de carreira & 6,08 & 6,04 & 6,06 & 0,201 & 0,654 \\
Identidade & 6,42 & 6,44 & 6,43 & 0,071 & 0,790 \\
Entrincheiramento na carreira & $\mathbf{3 , 9 4}$ & $\mathbf{3 , 8 5}$ & $\mathbf{3 , 9 0}$ & 0,952 & 0,330 \\
Falta de alternativas de carreira & 3,21 & 3,19 & 3,20 & 0,028 & 0,868 \\
Custo emocional & 4,67 & 4,65 & 4,66 & 0,017 & 0,896 \\
Investimentos na carreira & 3,95 & 3,72 & 3,85 & 2,984 & 0,085 \\
\hline
\end{tabular}

Nota. Fonte: dados da pesquisa.

No entanto, o reflexo da natureza da IES, se pública ou privada, foi constatada por Rowe e Bastos (2007a), ao estudarem as dimensões instrumentais do comprometimento organizacional com a escala de Medeiros (2003). Rowe e Bastos (2007a) verificaram que os docentes das instituições privadas apresentam maior comprometimento instrumental do que os docentes de IES públicas. Estes dados induzem que as características da IES influenciam o comprometimento organizacional instrumental e não influenciam nenhum dos vínculos com a carreira. Ou seja, os vínculos com a carreira do docente do ensino superior são independentes do lugar em que este docente trabalha, se em IES pública ou privada.

\section{Vínculos com a Carreira e Produção Acadêmica}

Apresenta-se, neste segmento, o modelo desenvolvido para testar as relações entre os vínculos com a carreira e produção acadêmica, utilizando-se a modelagem de equações estruturais. Na Figura 1 observam-se os pesos padronizados da regressão dos construtos independentes (as dimensões dos vínculos com a carreira - comprometimento e entrincheiramento) sobre os construtos dependentes (indicadores de produtividade). As setas pontilhadas e em tonalidade clara são caminhos ou relações que não se mostraram significativos dos modelos.

Para conceber esse modelo levaram-se em conta os resultados da análise de validade discriminante em que o construto publicação de periódicos deve ser visto como construto dependente da orientação e coordenação de projetos/bolsa de produtividade de pesquisa. De fato, argumenta-se que uma lógica similar deverá prevalecer para o construto publicação em anais, pois a orientação possivelmente é uma das condições que leva a uma maior propensão a publicação de artigos em eventos científicos. Notadamente, cabe ressaltar que, para além da plausibilidade conceitual, a tentativa de processar o modelo com publicação e anais, como construtos de mesmo nível que orientação e projetos, gera estimativas de erros negativas, uma evidência notável da má especificação e impossibilidade de testar este modelo segundo esta lógica (Jöreskog \& Sörbom, 1989). Assim, procede-se ao teste do modelo de pesquisa propriamente dito, que relaciona os vínculos com a carreira, formados pelas dimensões do comprometimento e do entrincheiramento na carreira, com a produção acadêmica, cujos resultados podem ser vistos na Figura 1. 


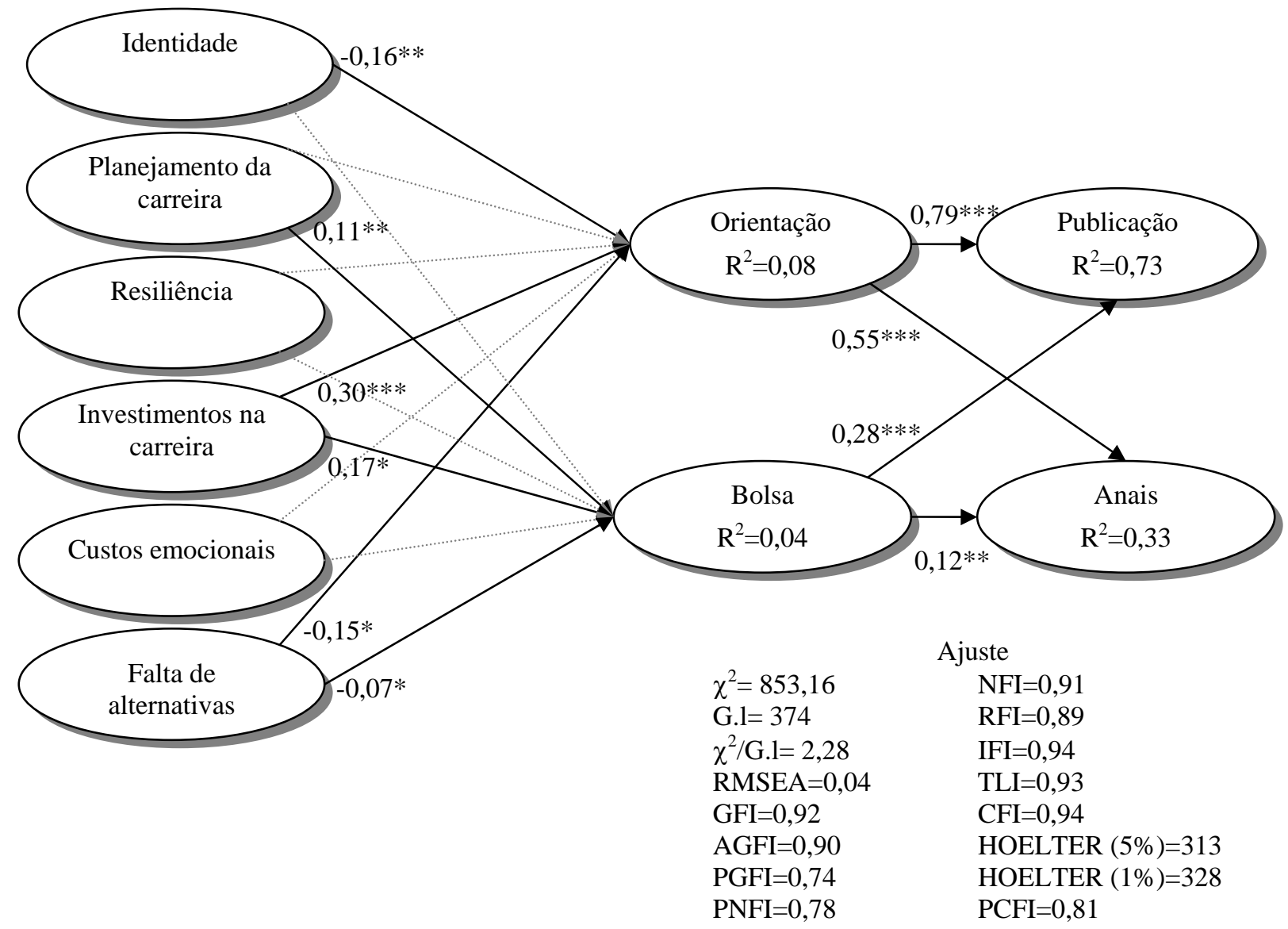

Figura 1. Modelo de Pesquisa: Vínculos Com a Carreira e Produção Acadêmica

*Significativo ao nível de $5 \%$ unicaudal $(\mathrm{p}<0,05)$; **Significativo ao nível de $1 \%$ unicaudal $(\mathrm{p}<0,01)$; ${ }^{* * *}$ Significativo ao nível de $0,1 \%$ unicaudal $(\mathrm{p}<0,001)$; $\mathrm{O} \mathrm{R}^{2}$ corresponde ao percentual de variância explicada.

Fonte: dados da pesquisa.

Observa-se na Figura 1 que ter bolsa de produtividade científica, coordenar projetos de pesquisas e orientar mestrandos e doutorandos são variáveis mediadoras entre os vínculos com a carreira e a produção acadêmica em periódicos e em anais.

Na Figura 1 pode-se dizer que o modelo explicativo da produção acadêmica apresenta um poder preditivo moderado dos construtos orientação de mestrado e doutorado e projeto/bolsa de pesquisa.

Nota-se que no presente modelo a dimensão afetiva - identidade (comprometimento com a carreira), que representa a identificação do docente com a sua carreira, a sua ligação emocional com a sua carreira e o grande significado pessoal da carreira para este docente - influencia orientação de forma negativa. Ressalta-se que resultado semelhante foi encontrado por Scheible et al. (2007), que encontraram correlação negativa entre o comprometimento afetivo com a carreira e o desempenho avaliado pelo superior $(r=-, 025)$ e positivo com a autoavaliação $(r=, 119)$.

A dimensão planejamento da carreira (comprometimento com a carreira) influencia positivamente e significativamente projeto/bolsa de pesquisa, conforme pode ser visualizado na Figura 1. Ressalta-se que Scheible et al. (2007) encontraram correlação significativa e positiva entre planejamento da carreira e desempenho avaliado pelo superior hierárquico $(\mathrm{r}=, 191)$. Estes resultados corroboram o seguinte: quanto mais o trabalhador leva em conta o seu desempenho profissional, possuindo uma estratégia para atingir seus objetivos de carreira, maior é o desempenho deste trabalhador.

A terceira dimensão da escala de comprometimento com a carreira, a resiliência, significa a percepção de que os desgastes associados à atividade profissional não são demasiados ou prejudiciais à vida pessoal. Refere-se, portanto, à capacidade para tolerar aspectos desagradáveis da atividade 
profissional e perceber os aspectos positivos como compensadores destas dificuldades. Esta dimensão não apresentou influência na produção acadêmica, conforme demonstra a Figura 1.

Interessante notar que o modelo dos vínculos com a carreira e produção acadêmica (Figura 1) tem na dimensão investimentos na carreira (entrincheiramento na carreira) o antecedente com maior preditivo de orientação de dissertação e tese e bolsa de produtividade acadêmica e coordenação de projetos de pesquisa. Estes resultados demonstram que quanto mais estes docentes investem tempo e dinheiro na capacitação profissional, a tendência é o aumento da sua produção acadêmica. Ou seja, os investimentos acumulados em uma carreira, que seriam perdidos ou menos aproveitados com uma mudança de carreira (Meyer \& Allen, 1984), no caso dos docentes do ensino superior, participantes deste estudo, se revertem em mais produção acadêmica. O caso destes docentes é explicado por Carson et al. (1996), quando apontam que alguns podem estar satisfeitos com seu entrincheiramento e com seu desenvolvimento. Coaduna-se com este resultado o apontamento de Carson et al. (1995), isto é, o fato de o trabalhador estar entrincheirado em sua carreira não acarreta, necessariamente, consequentes não bons para este trabalhador e/ou para sua organização empregadora, pois o trabalhador entrincheirado pode estar satisfeito ou resignado à sua situação e pode aceitar a condição de entrincheiramento. Vale mencionar que o docente do ensino superior é um profissional altamente qualificado, que dedica, consideravelmente, tempo e dinheiro em prol de sua carreira.

Ainda tratando-se do entrincheiramento na carreira, verifica-se na Figura 1 que sua dimensão falta de alternativas de carreira, que denota a percepção de poucas opções de carreira no caso de uma mudança de carreira, influencia negativamente a produção acadêmica, tanto no tocante à orientação de mestrandos e doutorandos quanto à bolsa de produtividade e coordenação de projeto. Estes resultados demonstram que quanto mais estes docentes percebem menos opções disponíveis em caso de mudança de carreira, devido a sua experiência e formação, menor é a sua produção acadêmica. Ressalta-se que, neste sentido, Scheible et al. (2007) encontraram correlação negativa $(\mathrm{r}=-, 269)$ entre esta dimensão do entrincheiramento, falta de alternativas, e o desempenho avaliado pelo superior hierárquico.

A terceira dimensão do entrincheiramento na carreira, custos emocionais, neste estudo não apresenta influência na produção acadêmica, conforme pode ser visualizado na Figura 1. Este resultado demonstra que a percepção do docente de que uma mudança de carreira pode acarretar ruptura de relações interpessoais, como perda de convivência com os colegas e do reconhecimento social, não influencia sua produção acadêmica.

Segundo Riketta (2002) e Scheible (2004), a relação entre comprometimento e desempenho não é direta, pois existem diversos fatores que modulam e moderam esta relação. Por sua vez, Ellemers e Heuvel (1998) alertam para o fato de que comprometimento não prediz desempenho na tarefa.

Verifica-se que no caso dos docentes do ensino superior aqui estudados, os vínculos com a carreira influenciam significativamente sua produção acadêmica.

Emerge uma curiosidade, após a análise das relações dos vínculos com a carreira com a produção acadêmica, que consiste em comparar os modelos explicativos da produção acadêmica de docentes de instituições públicas e privadas, por serem dois contextos assaz diferenciados de trabalho e de expectativas em relação ao desempenho docente.

\section{Comparação da Influência dos Vínculos com a Carreira na Produção Acadêmica entre Docentes de IES Públicas e Privadas}

Existem várias situações em que o pesquisador deseja saber se o modelo especificado se comporta de forma similar ao ser testado em grupos diferentes. Kline (1998) explica que a maneira mais simples de se resolver essa questão seria testar os grupos separadamente e depois inspecionar as soluções, por meio de estimativas não-padronizadas. No entanto, o autor adverte que existe uma forma mais sofisticada de fazer isso, usando a análise multigrupos. Nesse sentido, com o intuito de identificar perspectivas distintas para docentes vinculados a IES públicas e privadas foi utilizada a modelagem de 
equações estruturais com uma análise multigrupos. Este procedimento consiste em uma ferramenta adequada para comparar modelos de populações supostamente distintas (Tabachnick \& Fidell, 2001).

Na Tabela 6 notam-se as diferenças entre IES públicas e privadas, quando se trata dos vínculos com a carreira e da produção acadêmica.

Tabela 6

Modelo dos Vínculos com a Carreira e Produção Acadêmica: Comparação por Grupo de Docentes - IES Públicas e Privadas

\begin{tabular}{|c|c|c|c|}
\hline \multicolumn{2}{|c|}{ CONSTRUTOS } & \multicolumn{2}{|c|}{ GRUPO DE IES } \\
\hline INDEPENDENTES & DEPENDENTES & \multirow{2}{*}{ PÚBLICAS } & \multirow{2}{*}{ PRIVADAS } \\
\hline Vínculos com a carreira & Producão acadêmica & & \\
\hline
\end{tabular}

\section{Entrincheiramento na carreira}

Investimentos na carreira

Custos emocionais

Falta de alternativas de carreira

$\begin{array}{ccc}\begin{array}{c}\text { Bolsa de produtividade acadêmica e } \\ \text { coordenação de projetos }\end{array} & 0,13^{*} & 0,13^{*} \\ & 0,05 & 0,05 \\ & -0,09 & -0,09 \\ \mathrm{R}^{2} \text { públicas }=0,04 & -0,03 & -0,03 \\ \mathrm{R}^{2} \text { privadas }=0,04 & 0,11^{*} & 0,11^{*} \\ & -0,06 & -0,06\end{array}$

\section{Comprometimento com a carreira}

Identidade

Planejamento de carreira

Resiliência

\section{ORIENTAÇÕES}

(mestrado e doutorado)

Custos emocionais

Falta de alternativas de carreira

\section{Comprometimento com a carreira}

Identidade

Planejamento de carreira

Resiliência

\section{Produção acadêmica}

Bolsa de produtividade científica e coordenação de projetos

Orientações de mestrado e doutorado

Orientações de mestrado e doutorado

Bolsa de produtividade científica e coordenação de projetos

\begin{tabular}{ccc} 
& $-0,02$ & $-0,02$ \\
& $-0,14^{* *}$ & $-0,14^{* *}$ \\
& & \\
$\mathrm{R}^{2}$ públicas $=0,07$ & & \\
$\mathrm{R}^{2}$ privadas $=0,07$ & $-0,15^{*}$ & $-0,15^{*}$ \\
& 0,09 & 0,09 \\
Produção acadêmica & 0,05 & 0,05 \\
Publicação em anais & $0,12^{*}$ & $0,22^{*}$ \\
$\mathrm{R}^{2}$ públicas $=0,17$ & & \\
$\mathrm{R}^{2}$ privadas $=0,48$ & $0,39 * * *$ & $0,65^{* * *}$ \\
Publicação em periódicos & $0,93^{* * *}$ & $0,87^{* * *}$ \\
$\mathrm{R}^{2}$ públicas $=0,92$ & & \\
$\mathrm{R}^{2}$ privadas $=0,83$ & $0,21^{* * *}$ & $0,26^{*}$ \\
\hline
\end{tabular}

Nota. Fonte: dados da pesquisa.

*Significativo ao nível de 5\% unicaudal ( $<$ <0,05); **Significativo ao nível de $1 \%$ unicaudal $(\mathrm{p}<0,01)$; ***Significativo ao nível de $0,1 \%$ unicaudal $(\mathrm{p}<0,001) ; \mathrm{R}^{2}$ - percentual de variância explicada.

No modelo testado expresso na Tabela 6, as diferenças remetem aos pesos exercidos pela orientação e pela coordenação (projetos e bolsas) sobre a publicação em anais e periódicos. No caso de docentes vinculados a instituições privadas, as variáveis bolsa de produtividade científica, coordenação de 
projeto de pesquisa e orientação de mestrandos e doutorandos, exercem um forte impacto sobre a publicação em anais de congressos, explicando 48\% destas publicações, sendo considerável a diferença no caso de docentes de IES públicas: 17\%. Observa-se também que nas IES públicas estas variáveis (bolsa de produtividade científica, coordenação de projeto de pesquisa e orientação de mestrandos e doutorandos) têm maior impacto sobre a publicação em periódicos (92\%) do que nas IES privadas (83\%), apesar desta diferença ser menos expressiva.

Estes resultados da Tabela 6 refletem claramente a diferença da estrutura das IES públicas e privadas, quanto ao modo como a atividade de pesquisa se insere no cotidiano do trabalho docente. Ou seja, como as IES públicas são mais voltadas para a pesquisa, publicam mais em periódicos, que são publicações mais consistentes do que as comunicações em congressos.

Nesse mesmo sentido, tal resultado condiz com aqueles apontados por Rowe e Bastos (2007b), que realizaram uma pesquisa qualitativa entre docentes do ensino superior, encontrando como consequente do comprometimento no trabalho a produção acadêmica e a melhor estruturação da pesquisa somente entre os docentes de IES pública, vale dizer, os docentes de IES privadas não fizeram nenhuma menção acerca de que a produção acadêmica seja um consequente do comprometimento. Os resultados encontrados por esses autores coadunam-se com os resultados da presente pesquisa, no sentido de que, de forma geral, as IES públicas se dedicam mais à pesquisa do que as IES privadas.

Ressalta-se que esse estudo não teve a pretensão de utilizar todas as formas de avaliar o desempenho do docente, que envolveria, além da produção acadêmica, a avaliação do discente, a avaliação dos pares, a avaliação dos superiores e a autoavaliação. A presente escolha ocorreu devido a um necessário recorte do escopo da pesquisa, visando torná-la viável, quer em termos de coleta de dados, quer dos procedimentos de análise.

Essa pesquisa buscou verificar as diferenças e semelhanças entre o contexto público e privado em que se inserem as IES, porque a natureza dos contratos de trabalho existentes nestas instituições apresenta características bem distintas. Vínculos empregatícios que asseguram maior estabilidade no trabalho e um contexto para o desenvolvimento de atividades de pesquisa e extensão caracterizam a maioria das IES públicas, em oposição às instituições privadas.

\section{CONSIDERAÇÕES FINAIS}

Como afirmado anteriormente, a presente pesquisa insere-se em vertente que busca ampliar o conhecimento dos possíveis impactos do comprometimento no desempenho, uma reconhecida lacuna na área. Até então a pesquisa sobre comprometimento dedicou maiores esforços para identificar os preditores de comprometimento do que para avaliar as suas consequências ou possíveis impactos, principalmente quando se tomam indicadores de desempenho objetivos e independentes das percepções e julgamentos do próprio sujeito. No Brasil, são poucos os trabalhos voltados a preencher esta lacuna. Assim, a principal contribuição deste trabalho consiste em gerar novos conhecimentos dessa importante relação de comprometimento e desempenho no trabalho.

O estudo do docente de ensino superior ganha importância, em cenário de forte crescimento dessa categoria ocupacional, pela significativa expansão desse segmento de ensino, tanto no nível de graduação como na pós-graduação. Adicionalmente, por ser uma atividade na área de serviços, a qualidade do desempenho é fortemente determinada pela capacitação e motivação do indivíduo para com o seu trabalho. $\mathrm{O}$ fato de investigar tais fenômenos entre docentes do ensino superior, de instituições públicas e privadas e com uma amostra de abrangência nacional, garante a este estudo um caráter precursor que pode abrir linhas de investigação promissoras.

Como indicador do desempenho do docente adotou-se o quantitativo de produção acadêmica. Esta decisão se revelou interessante, pois permitiu captar o desempenho objetivo, medido a partir do lattes, 
proporcionando a criação de indicadores que agregam diferentes produções acadêmicas e que revelam perfis diferentes.

O objetivo do presente estudo foi delimitado em determinar as dimensões dos vínculos com a carreira - comprometimento e entrincheiramento - que explicam a produção acadêmica. Neste modelo, a dimensão investimentos na carreira (entrincheiramento na carreira) é o antecedente com maior poder preditivo de orientação de dissertação e tese, bolsa de produtividade científica e coordenação de projetos de pesquisa. Este estudo permite inferir o seguinte: quanto mais o docente investe tempo e dinheiro em sua carreira, maior é a sua produção acadêmica. Ou seja, os investimentos acumulados em uma carreira, que seriam perdidos ou menos aproveitados com uma mudança de carreira, no caso dos docentes do ensino superior participantes deste estudo, revertem em maior desempenho. Ainda tratando-se do entrincheiramento, sua dimensão falta de alternativas de carreira; ela denota a percepção de poucas opções de carreira no caso de mudança, influencia negativamente a produção acadêmica, tanto no tocante à orientação de mestrandos e doutorandos quanto à bolsa de produtividade e coordenação de projeto.

Este trabalho também buscou verificar as diferenças e semelhanças entre o contexto público e privado em que se inserem as IES, porque a natureza dos contratos de trabalhos existentes nestas instituições apresenta características bem distintas.

Embora os achados não tenham revelado relações de grande intensidade entre os vínculos com a carreira e a produção acadêmica, essas relações são significativas; merecem, portanto, mais investigação em outros contextos. Esse resultado, de influência moderada, não é surpreendente, por se saber que o produto do trabalho é consequência de um complexo de fatores situacionais e individuais: é concebível que a produção acadêmica não possa ser explicada unicamente pela natureza e intensidade dos vínculos com a carreira.

É importante salientar, no entanto, que os resultados aqui apresentados não podem, de forma automática, ser tomados como representativos do universo de docentes do ensino superior no Brasil, categoria extremamente ampla e não abrangida por métodos mais rigorosos de amostragem. Ressaltase que a amostra desta pesquisa não tem garantia de aleatoriedade nem assegura uma representatividade, em proporção adequada, de todos os docentes existentes em suas peculiaridades. No entanto, considerando que a preocupação deste estudo é a relação entre os fenômenos antes não investigados, a amostra obtida é suficiente para as análises realizadas.

O recorte de utilizar os modelos de vínculos com a carreira propostos por Carson e Bedeian (1994, 1995) e o fato de lidar com uma categoria ocupacional pouco estudada limitam a possibilidade de comparação dos resultados com outros similares na literatura.

O estudo não se esgota aqui. Pelo contrário, em função de outras possibilidades de pesquisa que não foram tratadas neste trabalho, continuar é preciso. Por isso são apresentadas, a seguir, algumas sugestões para pesquisas futuras.

Estudos subsequentes poderiam examinar a influência dos vínculos com a carreira na produção acadêmica do docente de ensino superior, por área de conhecimento: Ciências Exatas e da Terra; Ciências Biológicas; Engenharias; Ciências da Saúde; Ciências Agrárias; Ciências Sociais Aplicadas; Ciências Humanas; e Linguística, Letras e Artes. Desta forma, será possível verificar se há diferenças de produção acadêmica entre as áreas do conhecimento, com aprofundamento das particularidades de cada área. Também há a necessidade da relação dos vínculos com a carreira com outros indicadores de desempenho docente, como, por exemplo, indicador referente ao ensino.

Em síntese, o presente trabalho, além de permitir ampliar o conhecimento das relações entre as dimensões dos vínculos com a carreira e o desempenho no trabalho, abre perspectivas de novos estudos que façam avançar mais ainda o conhecimento científico deste importante tópico do campo de estudos organizacionais. 
Artigo recebido em 28.12.2009. Aprovado em 27.09.2010.

\section{REFERÊNCIAS BIBLIOGRÁFICAS}

Anteprojeto de lei da educação superior de 29 de julho de 2005. (2005). Exposição de motivos. Brasília, DF: Ministério da Educação.

Aryee, S., \& Tan, K. (1992). Antecedents and outcomes of career commitment. Journal of Vocational Psychology, 40(3), 288-305.

Baiocchi, A., \& Magalhães, M. (2004). Relações entre processos de comprometimento, entrincheiramento e motivação vital em carreiras profissionais. Revista Brasileira de Orientação Profissional, 5(1), 63-71.

Bastos, A. V. B. (1994). Múltiplos comprometimentos no trabalho: a estrutura dos vínculos do trabalhador coma organização, a carreira e o sindicato. Tese de doutorado, Universidade de Brasília, Brasília, DF, Brasil.

Bastos, A. V. B. (1997). A escolha e o comprometimento com a carreira: um estudo entre profissionais e estudantes de administração. Revista de Administração da USP, 32(3), 28-39.

Blau, G. (2001). On assessing the construct validity of two multidimensional constructs: occupational commitment and occupational entrenchment. Human Resource Management Review, 11(3), 279-298.

Blau, G. (2003). Testing for a four-dimensional structure of occupational commitment. Journal of Occupational and Organizational Psychology, 76(4), 469-488.

Carson, K. D., \& Bedeian, A. (1994). Career commitment: construction of a measure and examination of its psychometric properties. Journal of Vocational Behavior, 44(3), 237-262.

Carson, K. D., \& Carson, P. P. (1997). Career entrenchment: a quiet march toward occupational death? Academy Of Management Executive, 11(1), 62-75.

Carson, K. D., Carson, P., \& Bedeian, A. (1995). Development and construct validation of a career entrenchment measure. Journal of Occupational and Organizational Psychology, 68(4), 301320.

Carson, K. D., Carson, P. P., Phillips, J. S., \& Roe, C. W. (1996). A career entrenchment model: theoretical development and empirical outcomes. Journal of Career Development, 22(4), 273286.

Cohen, A. (2003). Multiple commitments in workplaces: an integrative approach. Mahwah, New Jersey: Lawrence Erlbaum Associates.

Cooper-Hakim, A., \& Viswesvaran, C. (2005). The construct of work commitment: testing an integrative framework. Psychological Bulletin, 131(2), 241-259.

Ellemers, N., \& Heuvel, D. van den (1998). Career-oriented versus team-oriented commitment and behavior at work. Journal of applied psychology, 83(5), 717-730.

Gottlieb, M. R., \& Conkling, L. (1995). Managing the workplace survivors: organizational downsizing and the commitment gap. Westport, Connecticut: Quorum Books. 
Hair, J. F., Jr., Anderson, R. E., Tatham, R. L., \& Black, W. C. (2005). Análise multivariada de dados (5a ed.). Porto Alegre: Bookman.

Hirsch, P. (1987). Pack your own parachute: how to survive mergers, takeovers, and other corporate disasters. Reading, MA: Addison-Wesley.

Jardim, F. (2002). Relações entre prioridades axiologias e comprometimento com a carreira. Monografia de graduação, Universidade Luterana do Brasil, Canoas, RS, Brasil.

Jöreskog, K. G., \& Sörbom, D. (1989). LISREL ${ }^{\circledR} 7$ A guide to the program and applications (2nd ed.). Uppsala, Sweden: SPSS.

Kidd, J. M., \& Green, F. (2006). The careers of research scientists: predictors of three dimensions of career commitment and intention to leave science. Personnel Review, 35(3), 229-251.

Kline, R. B. (1998). Principles and practice of structural equation modeling. New York: The Guilford Press.

Lee, K., Carswell, J., \& Allen, N. (2000). A meta-analytic review of occupational commitment: relations with person and work-related variables. Journal of Applied Psychology, 85(5), 799811.

Lei n. 9.394, de 20 de dezembro de 1996. (1996). Estabelece as diretrizes e bases da educação nacional. Recuperado em 20 outubro, 2010, de http://www.planalto.gov.br/ccivil_03/Leis/L9394.htm

Magalhães, M. O. de (2005). Personalidades vocacionais e desenvolvimento na vida adulta: generatividade e carreira profissional. Tese de doutorado, Universidade Federal do Rio Grande do Sul, Porto Alegre, RS, Brasil.

Malhotra, N. (2006). Pesquisa de marketing: uma orientação aplicada (4a ed.). Porto Alegre: Bookman.

Mathieu, J., \& Zajac, D. (1990). A review and meta-analysis of the antecedents, correlates, and consequences of organizational commitment. Psychological Bulletin, 108(2), 171-194.

Meyer, J. P., \& Allen, N. J. (1984). Testing the "side-bet theory" of organizational commitment: some methodological considerations. Journal of Applied Psychology, 69(3), 372-378.

Moita, M. H. V. (2002). Um modelo para avaliação da eficiência técnica de professores universitários utilizando análise de envoltória de dados: o caso dos professores da área de engenharias. Tese de doutorado, Universidade Federal de Santa Catarina, Florianópolis, SC, Brasil.

Morrow, P. C. (1983). Concept redundancy in organizational research: the case of work commitment. Academy of Management Review, 8(3), 486-500.

Oliveira, M. A. P. S. (1998). Comprometimento organizacional e com a carreira: influência sobre a produção acadêmica de pesquisadores brasileiros. Dissertação de mestrado, Universidade de Brasília, Brasília, DF, Brasil.

Riketta, M. (2002). Attitudinal and organizational commitment and job performance: a meta-analysis. Journal of Organizational Behavior, 23(3), 257-266.

Rowe, D. E. O., \& Bastos, A. V. B. (2007b, junho). Comprometimento no trabalho: explorando o conceito, seus antecedentes e conseqüentes entre docentes universitários. Anais do Encontro de Gestão de Pessoas e Relações de Trabalho, Natal, RN, Brasil, 1. 
Rowe, D. E. O., \& Bastos, A. V. B. (2007a, setembro). Organização e/ou carreira? Comparando docentes de IESs públicas e privadas quanto à estrutura de seus vínculos de comprometimento no trabalho. Anais do Encontro Nacional da Associação Nacional de Pós-Graduação e Pesquisa em Administração, Rio de Janeiro, RJ, Brasil, 31.

Scheible, A. C. F. (2004). Comprometimento no trabalho: um estudo de caso de suas relações com desempenho e práticas de gestão. Dissertação de mestrado, Universidade Federal da Bahia, Salvador, BA, Brasil.

Scheible, A. C. F., \& Bastos, A. V. B. (2006, setembro). Comprometimento na carreira: explorando o conceito de entrincheiramento. Anais do Encontro Nacional da Associação Nacional de PósGraduação e Pesquisa em Administração, Salvador, BA, Brasil, 30.

Scheible, A. C. F., Bastos, A. V. B., \& Rodrigues, A. C. A. de (2007, setembro). Comprometimento e entrincheiramento: integrar ou reconstruir? Uma exploração das relações entre estes construtos à luz do desempenho. Anais do Encontro Nacional da Associação Nacional de Pós-Graduação e Pesquisa em Administração, Rio de Janeiro, RJ, Brasil, 31.

Somech, A., \& Bogler, R. (2002). Antecedents and consequences of teacher organizational and professional commitment. Educational Administration Quarterly, 38(4), 555-577.

Tabachnick, B. G., \& Fidell, L. S. (2001). Using multivariate statistics (3a ed.). New York: HarperCollins.

Vergara, S. C. (2007). Projetos e relatórios de pesquisa em administração (8a ed.). São Paulo: Atlas.

Wallace, J. E. (1993). Professional and organizational commitment: compatible or incompatible? Journal of Vocational Behavior, 42(3), 333-349. 